\title{
Radiotherapy and inhibition of the EGF family as treatment strategies for prostate cancer: combining theragnostics with theragates
}

\author{
Wolfgang Lilleby $\cdot$ Flavio Solca $\cdot$ Kathrine Røe
}

Received: 30 August 2010/ Accepted: 8 November 2010/Published online: 16 December 2010

(C) The Author(s) 2010. This article is published with open access at Springerlink.com

\begin{abstract}
Prostate cancer is one of the most common solid tumors affecting men. Localized stages can be cured, however, once disseminated to distant organs the median survival drops below 12 months. The challenge for the future consists of unifying gained insights of cellular signal dysfunctioning ("theragates") with the knowledge of disease detection ("theragnostics") in personalized therapy. In solid malignancies, multiple signal transduction molecules are often deregulated simultaneously, within the same tumor. A multi-targeted approach may possibly improve efficacy, but will also increase toxicity, thus, potentially limiting the use of various combinations. On the other hand, well-established treatment modalities in prostate cancer, such as radiotherapy with its known efficacy and limited toxicity, may be an attractive combination partner for protein kinase inhibitors. Deregulation of the epidermal growth factor receptor (EGFR) signal transduction pathway is observed in a variety of solid tumors, including prostate cancer. Furthermore, one important DNA repair mechanism
\end{abstract}

\section{W. Lilleby}

Department of Oncology, The Norwegian Radium Hospital,

Oslo University Hospital, 0310 Oslo, Norway

F. Solca

Department of Pharmacology,

Boehringer Ingelheim RCV GmbH \& Co KG,

1121 Vienna, Austria

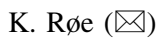

Department of Radiation Biology, Institute for Cancer Research,

The Norwegian Radium Hospital, Oslo University Hospital,

0310 Oslo, Norway

e-mail: Kathrine.Roe@rr-research.no

K. Røe

Institute of Clinical Medicine, University of Oslo,

0318 Oslo, Norway is dependent on EGFR nuclear translocation, thus, providing a rationale for combining radiotherapy with EGFR inhibitors. This article reviews current knowledge regarding this combination paradigm, revealing an intriguing therapy option to be explored for patients with advanced prostate cancer.

Keywords Prostate cancer - EGF - HER2 .

Radiotherapy · Theragnostics · Theragates

\section{Introduction}

Prostate cancer (PCa) represents a paradigm of hormonedriven malignancy. In patients with localized or locally advanced disease, the combination of hormonal treatment with radiotherapy has shown synergistic effects resulting in improved survival rates [1]. Patients with distant disease are usually restricted to treatment with systemic therapy primarily applying androgen manipulation either as androgen deprivation or androgen blockade, or both. Despite high response rates initially, all patients with metastatic disease treated with androgen deprivation will eventually progress and become clinically refractory to androgen manipulation (Fig. 1). In these patients, conventional conformal, external beam radiation or surgery are mainly used in symptomatic patients with focally limited problems. The aim of this approach is to prevent local symptoms and to achieve long-lasting local control without increasing local morbidity. However, in patients with advanced disease the outcome is dismal.

A multi-targeted approach may possibly improve survival, but will also increase toxicity. In this situation, wellstudied modalities in $\mathrm{PCa}$, such as radiotherapy with its known efficacy and limited toxicity, may be an interesting 
Fig. 1 In patients with localized or locally advanced PCa the combination of androgen deprivation therapy $(A D T)$ with radiotherapy $(R T)$ has shown synergistic effects. Despite high response rates initially, all high-risk patients treated with ADT will eventually progress into an incurable androgen resistant disease, becoming clinically refractory to androgen manipulation

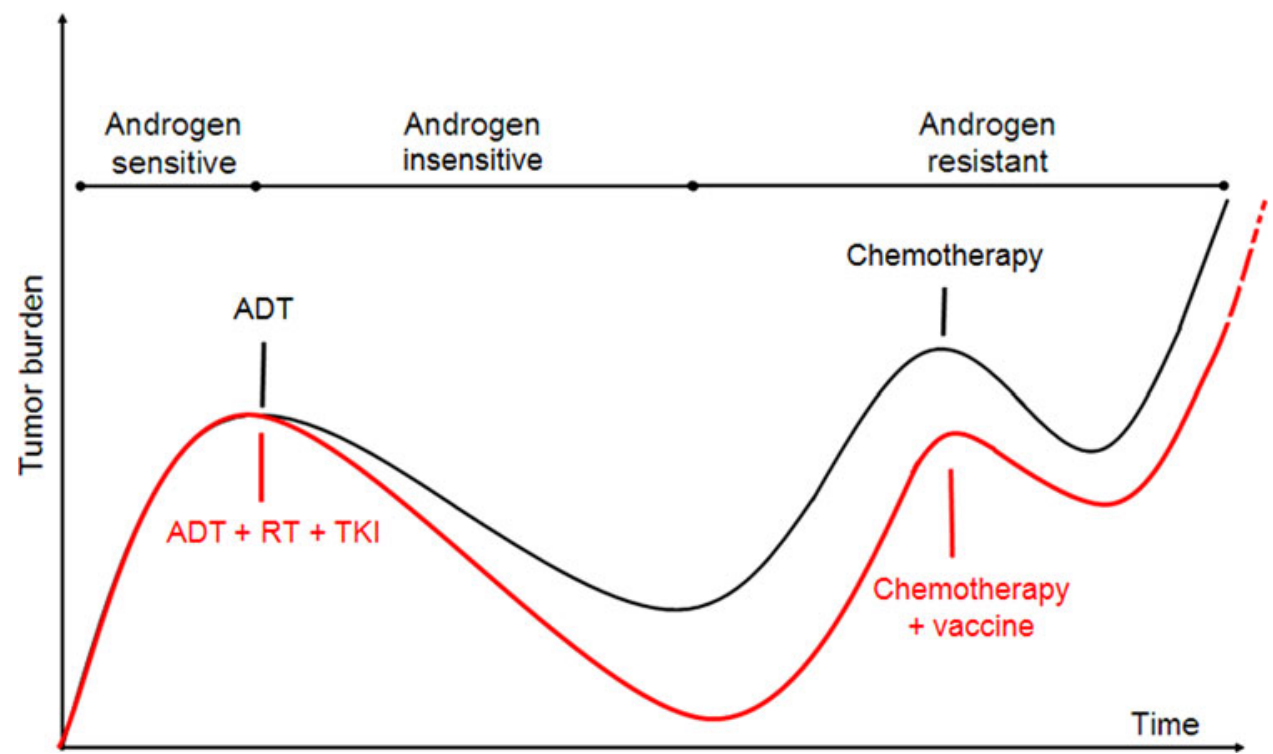

combination partner with tyrosine kinase inhibitors (TKIs) [2]. However, sustained tumor control by radiotherapy is depending on a variety of issues including tumor heterogeneity and intrinsic biological factors like hypoxia, cell proliferation, apoptosis, angiogenesis and radiation resistant gene expression, resulting in tumor cell survival and regrowth. The metastatic potential is essentially influenced by hypoxia, leading to robust circulating cells with acquired stem cell-like properties characterized by the epithelial-mesenchymal transition (EMT), being able to escape androgen manipulation [3].

To further improve the outcome of patients with metastatic $\mathrm{PCa}$, suitable molecular biomarkers and functional imaging may be utilized in identification of differently aggressive areas in a biologically inhomogeneous tumor mass that can be individually and more appropriately targeted using innovative image guided radiotherapy (IGRT) and improved intensity modulated radiotherapy, both by external irradiation (IMRT) and brachytherapy (IMBT). Thus, a combination of therapy and diagnostics ("theragnostics") may take morphological and functional properties of the tumor into account, also utilizing non-invasive imaging modalities like dynamic contrast-enhanced magnetic resonance imaging (MRI), diffusion-weighted MRI and MR spectroscopy in order to acquire valuable information about metabolic composition, vascularization, hypoxia and structure (Fig. 2), and translate these into a personalized targeted therapy ("theragates") [4-8].

Recent findings indicate that epidermal growth factor (EGF) signalling is an important mediator of radiotherapy resistance and promotion of metastasis. Similar to "theragnostics", tumor hypoxia and the impact of EGF pathways for tumor progression might be studied by phenotypically characterized detached cells, representing a potential biomarker that can be used in monitoring therapeutic efficacy. Clinical trials to address these new avenues in multimodal therapy of PCa ("theragates") should be encouraged. This article reviews currently available state-of-the-art knowledge of the EGF family in patients with advanced PCa.

\section{EGFR}

EGFR is a receptor tyrosine kinase (RTK) belonging to the ErbB receptor family that comprises four members (ErbB1/ EGFR/human epidermal growth factor receptor 1 (HER1), ErbB2/HER2/neu, ErbB3/HER3, and ErbB4/HER4), and is known to control the behavior of normal epithelial cells and tumors of epithelial cell origin [9]. This growth factor receptor system is deregulated in many human tumors, including PCa [10]. Elevated EGFR expression is for instance associated with the poor clinical prognosis and resistance to chemotherapy, hormone therapy, and radiotherapy [11, 12].

Structurally, EGF family receptors present an extracellular ligand binding domain, a transmembrane domain, and a cytoplasmic domain which harbors the intrinsic tyrosine kinase (TK) activity. Dimerized, transphosphorylated EGF receptors activate complex and dynamic signaling cascades that result in specific gene transcription controlling cell cycle progression, tissue homeostasis, survival and invasion. In a cancer cell, aberrant EGFR signaling promotes increased proliferation, invasion, migration, differentiation and enhanced survival by stimulating anti-apoptotic pathways $[10,13]$.

The intracellular tyrosine kinase domain of EGF receptors is highly conserved. Oppositely, the extracellular domains of EGF receptors are less conserved, and able to bind to different ligands. The EGF ligand family includes 


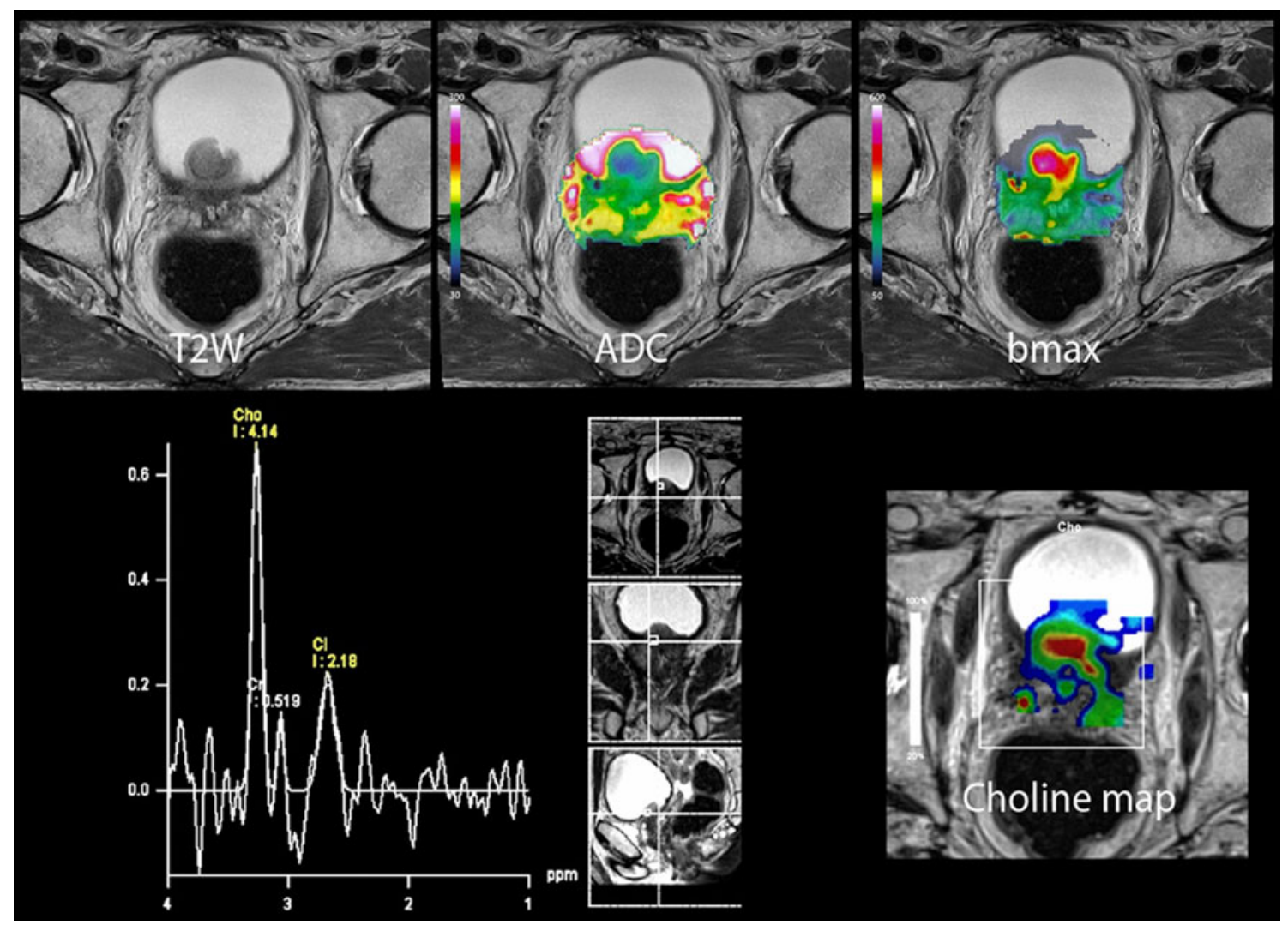

Fig. 2 The combination of therapy and diagnostics ("theragnostics") might involve non-invasive visualization of underlying molecular and tumorphysiological mechanisms by employing imaging techniques like morphological T2-weighted magnetic resonance imaging (MRI) (upper left), diffusion-weighted MRI (upper mid and right) and MR spectroscopy with metabolite quantification, e.g., the (creatine + choline)/citrate

over ten different molecules, including EGF, heparinbinding EGF (HB-EGF), betacellulin (BTC), transforming growth factor $\alpha$ (TGF- $\alpha$ ), epiregulin (EPR), amphiregulin (AR) and five different neuregulins (NRG-1 to NRG-5) [13]. The ligands that specifically bind to EGFR are EGF, TGF- $\alpha$, AR and the newly identified ligand epigen [14, 15], while BTC, HB-EGF and EPR bind both to EGFR and other members of the EGF family. Ligand binding induces or stabilizes receptor homo- or heterodimerization with other EGF receptors [13]. Subsequently, tyrosine kinases are activated, and transphosphorylation of the dimerization partner occurs. The newly phosphorylated tyrosine residues act as docking sites for intracellular signaling molecules, which further induce different downstream signaling pathways, dependent on the receptor pair combination. These pathways include the Ras-Raf-mitogen-activated protein kinase (MAPK) cascade, the phosphoinositide 3-kinase (PI3K)-Akt cascade, the Janus kinase (JAK) and the signal transducer and activator of transcription (STAT) cascade, as well as the protein kinase $\mathrm{C}$ (PKC) cascade $[13,16,17]$. Figure 3 illustrates some of the complex signaling interactions derived from EGF receptors. ratio (lower panel). These techniques can be used to obtain valuable information that may be utilized in the development of a personalized targeted therapy ("theragates"). (Courtesy of Knut Håkon Hole, MD, Department of Radiology, The Norwegian Radium Hospital, Oslo University Hospital, Oslo, Norway)

Because aberrant activation of EGF receptors has been associated with uncontrolled cell proliferation and survival, targeting members of the EGFR family seems to be an attractive and logical option for cancer therapy. Further, activation of EGFR signaling has been reported to be mediated by ionizing radiation. Thus, exposure of EGFR overexpressing tumor cells to ionizing radiation is expected to activate survival and proliferation mechanisms predominantly through PI3K-Akt and Ras-Raf-MAPK signaling pathways, which subsequently inhibits apoptosis and promotes cell proliferation and repopulation [16, 18, 19]. As a consequence, activation of these two pathways is thought to be the main causes of radiotherapy resistance of EGFR overexpressing tumors [16, 18, 20, 21].

\section{HER2, HER3, HER4 and the androgen receptor}

HER2 (or ErbB2) is unique within the EGF receptor family since its extracellular domain is fixed in the active conformation, permanently exposing its dimerization arm, thus, resembling a ligand activated EGF receptor. These structural 


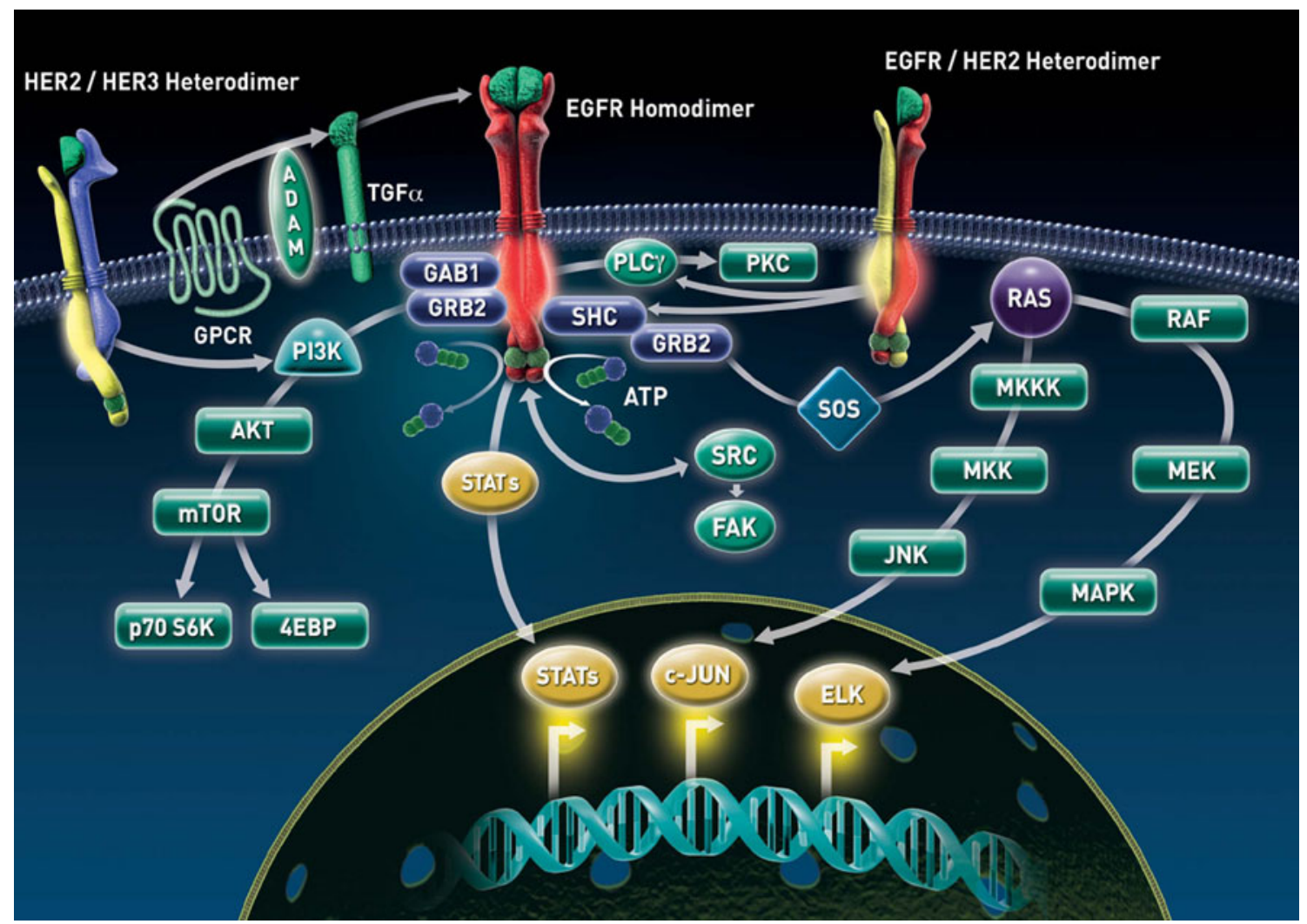

Fig. 3 The epidermal growth factor $(E G F)$ receptor family, also known as the ErbB receptor family, consists of four different members; EGFR, human epidermal growth factor receptor $(H E R) 2$, HER3 and HER4. Besides transforming growth factor $\alpha$ (TGF- $\alpha)$, at least ten additional ligands with various EGF receptor affinities have been described. Ligand binding has been reported to stabilize the

observations provide an explanation as to why no ligand for HER2 has been identified so far, and suggest that HER2 dimerization does not require ligand binding [10]. HER2 is, therefore, always available and is the preferred heterodimerization partner for other ligand-bound ErbB receptors.

HER3 (ErbB3) lacks essential catalytic residues and is most likely unable to transphosphorylate its dimerization partner although an alternative enzymatic mechanism has recently been postulated [22]. HER3, on the other hand, is a potent inducer of the PI3K-Akt pathway [23]. It is also of note that the HER2 (no ligand)/HER3 (no kinase) heterodimers have been reported as the strongest signaling receptor dimers in reconstituted biological systems [10]. HER4 (ErbB4) is the most recent member in the EGF receptor family and is much less characterized. HER4 not only transduces signals the standard way (homo- and/or heterodimerization), but also acts as a direct transcriptional regulator when activated by the proteolytic processing pathway (metallo protease and $\gamma$-secretase) [24].

The androgen receptor (AR) is a key molecular determinant in the progression of PCa towards the hormonerefractory state of the disease. Studies have shown that various combinations of receptor homo- and heterodimers, thereby promoting close vicinity of the intracellular kinase domains. This results in receptor transactivation, leading to engagement of downstream signaling pathways, which ultimately result in gene transcription controlling cell cycle progression, tissue homeostasis, survival and invasion

EGF kinase signals are mandatory for optimal AR functioning at low androgen concentrations and that these signals are not mediated through EGFR, but rather through the association of HER2 with other members of the EGF receptor family. Thus, overexpression of HER2 may enhance AR function and consequently also promote androgen resistant growth $[25,26]$. Recently, Jain et al. [27] also demonstrated that EGFR kinase inhibition caused oncogenic switch to HER2 signaling in a preclinical study. Thus, the strong involvements of both EGFR and HER2 in cell signaling pathways make both receptors attractive targets for therapeutic intervention, separately as monotarget inhibition, but particularly as dual-targeted therapy.

\section{EGF and radiotherapy}

Multiple evidences indicate that elevated EGFR expression is an important determinant of radiation response and that EGFR exhibits a radioprotective function [16, 18, 20, 21]. The radiation resistance is mainly thought to occur due to the activation of signaling cascades leading to tumor cell 
survival, repopulation and proliferation. Recent studies have identified novel radioprotective mechanisms of EGFR, where EGFR is shown to be involved in radiationinduced nuclear translocation of the receptor and interactions with the DNA-dependent protein kinases (DNA-PKs), being the main components in the non-homologous end-joining (NHEJ) DNA repair pathway [18].

The radioprotective functions mediated by EGFR can be separated into three phases as function of time (Fig. 4) [18]:

1. Early phase of DNA repair $(0-4 h)$ This phase involves radiation-induced translocation of EGFR and interactions with the DNA repair enzyme, DNA-PK. EGFR is present in the perinuclear space of unirradiated cells. After irradiation, ligand-independent translocation of the EGFR into the nucleoplasm is induced by a process involving free radicals [28, 29]. Further, nuclear EGFR binds to the catalytic regulatory subunits of DNA-PK, DNA-PKcs, and the regulatory subunits $\mathrm{Ku} 70$ and Ku80 of DNA-PK. The interaction of EGFR with DNA-PKcs relates to radiation-induced DNA-PKcs phosphorylation which controls the disassembly of DNA-PKcs and

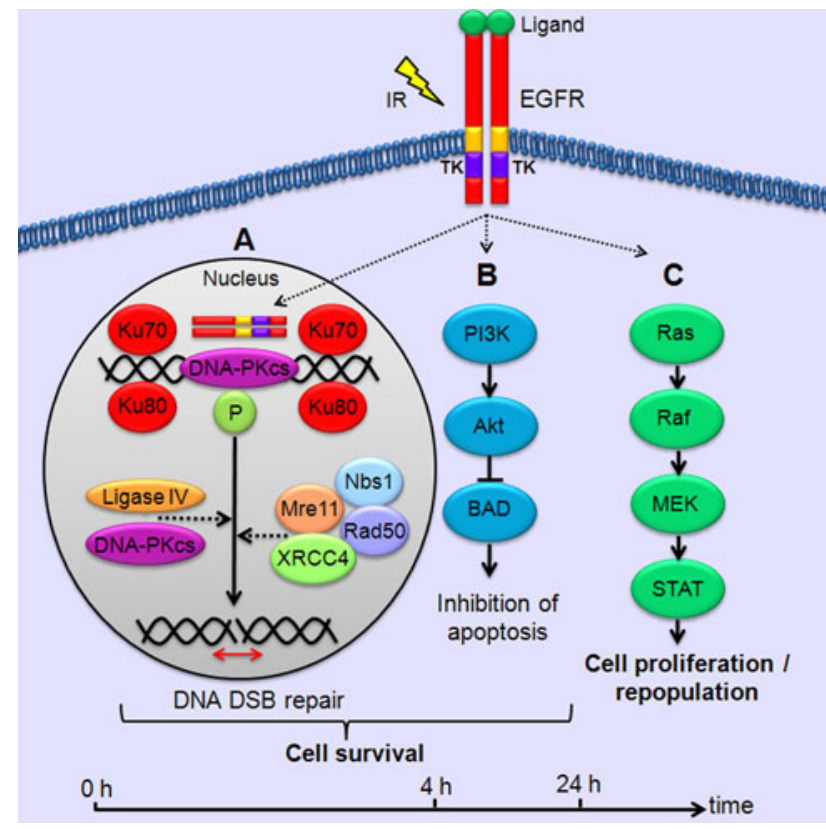

Fig. 4 The radioprotective functions mediated by EGFR can be separated into three phases as function of time. a The early phase of DNA repair where EGFR is translocated into the nucleus, interacting with the regulatory DNA-PK subunits DNA-PKcs, Ku70 and Ku80, controlling the rejoining of DNA double strand breaks (DSBs). b The phase of inhibition of radiation-induced apoptosis, where activation of EGFR promotes PI3K and Akt activation, thus, suppressed apoptosis. c The proliferation and repopulation phase where EGFR activation causes tumor cells to emerge from radiation-induced cell cycle arrest and activate the Ras/Raf/MEK/ERK and STAT pathways, promoting cell survival the rejoining of DNA double strand breaks (DSBs), thus leading to cell survival [28].

2. Inhibition of DNA damaged-induced apoptosis phase (4-24 h) Normally, tumor cells undergo rapid apoptotic cell death either prior to cell division or during a second phase where cells with unrepaired DSBs emerge from radiation-induced cell cycle arrest. Oppositely, radiation-induced activation of EGFR has been shown to confer resistance to apoptosis through activation of the PI3K and Akt signaling pathway, thus, cell survival is maintained [30, 31].

3. Proliferation and repopulation phase $(>24 h)$ The cells emerging from radiation-induced cell cycle arrest after repair of DNA damage exhibit a proliferation and repopulation advantage, since the EGFR-dependent Ras/Raf/MEK/ERK and STAT signaling pathways are activated, thus, a survival advantage is supported [32].

These findings suggest that it might be possible to sensitize tumors to radiation by blocking the radiation-induced nuclear import of EGFR by treatment with EGFR (and HER2) inhibitors. Jooensu et al. [33] recently showed additive effects combining gefitinib with radiotherapy in patients with $\mathrm{PCa}$ in a phase I/II trial.

\section{Relation to hypoxia}

Studies have shown upregulation of EGFR expression under hypoxic conditions. Thus, hypoxia is expected to be reduced after treatment with EGFR inhibitors, possibly leading to an improvement in local tumor control after irradiation [20, 21]. In addition to the adaptive changes induced by hypoxia on EGFR, interactions also exist between EGFR and angiogenesis, as shown by the antiangiogenic activity of EGFR inhibitors. In vitro, reduced expression of vascular endothelial growth factor (VEGF) has been shown after incubation with gefitinib, an EGFR tyrosine kinase inhibitor (TKI) [34, 35]. In vivo, reduced vessel density has been shown after both mAb and EGFR TKI application, where the effect also was apparent after combination of the EGFR inhibitor with radiation [35]. In this respect, the concept of normalization of vasculature, which has been observed following treatment with antiangiogenic therapies, also needs to be considered. Whereas the vision of anti-angiogenic therapies originally was to destroy the tumor vasculature in order to reduce oxygen and nutrient status of the tumors, these therapies may also transiently lead to a balance between anti-angiogenic and pro-angiogenic factors and, thus, normalization of the tumor vasculature, making it more efficient for oxygen and drug delivery [36]. Thus, such anti-angiogenic therapy may theoretically both improve and impair tumor oxygenation 
status, and thereby modulate the effects of radiotherapy in opposite directions [37]. Our recent preclinical study in androgen sensitive PCa xenografts also revealed that tumor vascularization and oxygen status are affected by androgen deprivation treatment strategies, further influencing the response to subsequent radiotherapy [38]. Thus, the timing of such therapeutic interventions in relation to tumor vascularization status is an important aspect that needs to be considered.

Further, both cetuximab and gefitinib have shown to downregulate hypoxia-inducible factor alpha (HIF-1 $\alpha$ ) [39]. Downregulation of HIF- $1 \alpha$ may thus be a positive marker to EGFR-targeted therapy. EGF is abundantly found in bone marrow and is triggering signals in osteoblast progenitor cells [15]. The homing niche for micrometastasis is apparently a hostile environment with low $\mathrm{pH}$, acidity and predominantly hypoxic conditions. Micrometastatic founder cells adapted to such a micromilieu will have greater chances to survive. This model of oncogenic addiction was also recently supported by Brandt et al. in a study describing HER-dependent upregulation of the unfolded protein response (UPR) as an adaptation mechanism in breast carcinoma [40, 41].

\section{EGF family inhibitors}

Because all four EGF receptors most of the time are simultaneously expressed at the cell surface of tumor cells, and because homo- as well as heterodimers are formed upon growth factor activation, dual inhibition targeting both EGFR and HER2 has attracted significant interest and research during the last few years. By broadening the scope of EGF receptor dimer inhibition and by providing a complete block (both partners) of all cancer relevant EGF dimers, a combined treatment targeting both EGFR and HER2 is likely to improve the antitumor activity compared to inhibition of only one of the receptors.

First generation small molecule EGFR tyrosine kinase inhibitors (e.g., gefitinib or erlotinib) have shown to be effective against EGFR overexpressing tumors. Despite initial responses patients often develop resistance to these inhibitors, causing relapse of the tumors. Of note, a phase III trial including inoperable stage III non-small-cell lung cancer patients showed that patients receiving gefitinib did not improve survival compared to the placebo group [42]. The study was closed before it reached its planned sample size, with the median survival time being 23 months for the gefitinib-treated patients and 35 months for the placebo group.

Mechanisms of resistance indicate the need for an inhibitor that is more broadly active against EGF receptor tyrosine kinases. In vitro, irreversible inhibitors (e.g., EKB569, HKI-272, PF299, 804 and BIBW2992) that covalently bind and irreversibly inhibit the activity of EGFR and/or HER2 have shown increased efficacy against cell lines expressing EGFR mutants resistant to gefitinib and erlotinib [43-45]. One of these inhibitors, BIBW2992 (afatinib), is a new irreversible dual specificity EGFR and HER2 inhibitor designed to covalently bind to Cys 773 of EGFR and Cys 805 of HER2 [46]. This inhibitor has demonstrated improvements over first-generation EGFR inhibitors in lung cancer and squamous cell carcinoma models [47-49]. Tolerability and pharmacokinetics of the inhibitor in patients have recently been investigated in a phase I study by Eskens et al. [50], and phase II results reporting clinical activity of the compound have been described [51-53].

The dual EGFR and HER2 inhibitor GW572016 (lapatinib) might currently be the inhibitor with the highest clinically significant value so far. First, in vitro studies demonstrated the inhibitor's growth-inhibitory effects in EGFR and HER2 overexpressing cell lines [54]. Further, two large randomized phase III studies investigated the addition of lapatinib to chemotherapy and one trial looked into the combined effect of endocrine therapy with lapatinib for patients with advanced breast cancer [55-57]. All studies showed significantly prolonged time to progression and to the primary endpoint, and on the basis of the achieved results, lapatinib was approved by the FDA.

\section{Predictive biomarkers}

The Prostate Cancer Clinical Trials Working Group 2 (PCCTWG2) recently advised against reporting prostate specific antigen (PSA) response rates because these are of little value given the uncertain significance of a defined degree of decline from baseline. The clinical decisionmaking should not be made on PSA measurements alone, but also be assisted by suitable biomarkers to critically select and evaluate patients. These predictive biomarkers may be able to categorize different molecular types of PCa. Biomarker studies are on their way and may help characterize resistance mechanisms, as has been seen in colon cancer for KRAS mutations [58]. In $\mathrm{PCa}$, preliminary studies suggest that circulating tumor cells (CTCs) can be used for monitoring treatment response. Thus, we propose that molecular characterization of CTCs will help identifying therapeutical targets.

During recent years the identification of cytokeratinpositive mononuclear cells in bone marrow (BM) and peripheral blood (PB) has become feasible using immunocytochemistry. In addition, molecular detection procedures relying on PSA, cytokeratin 19 or prostate-specific membrane antigen have been used extensively to identify the residual tumor cells in $\mathrm{BM}$ or $\mathrm{PB}$. In principle, the DNA of disseminated tumor cells (DTCs) or CTCs may 
also be isolated and amplified by the polymerase chain reaction (PCR), so that very small numbers of tumor cells can be detected. Over the last years, there has been a rapid development of technologies for isolating DTCs, employing enrichment methods for further characterization of these cells. The enumeration and characterization of CTCs in PB can be done by different devices using EpCAM coating as antibody in the CellSearch system [59], microfluid devices (CTC-chip) [60], or MagSweeper [61]. In addition, the latest techniques generate microvortices to significantly increase the number of interactions between CTCs and the antibody-coated chip surface. In a further RT-PCR step, RNA may be isolated to study tumorspecific gene locations. In all devices, the CTCs may subsequently be characterized by immunofluorescenceconjugated antibodies (Fig. 5).

In $90 \%$ of the patients with advanced $\mathrm{PCa}$, the disease metastasizes to the bone, also including skeleton involvement [62]. The reason for preferential establishment and growth of disseminated $\mathrm{PCa}$ in $\mathrm{BM}$ are still unknown. Although $70 \%$ of the patients have detectable DTCs in the pre-radical prostatectomy, only $10-25 \%$ of those with organ-confined PCa develop recurrence. The prediction of whether an individual patient will relapse with progressive disease years later is still difficult. While there have been numerous attempts to add prognostic power from other biological features, none has proven repeatedly to be of higher predictive value than the traditional Gleason score. However, in patients treated with curative treatment, detection of DTCs in BM has shown to be a prognostic

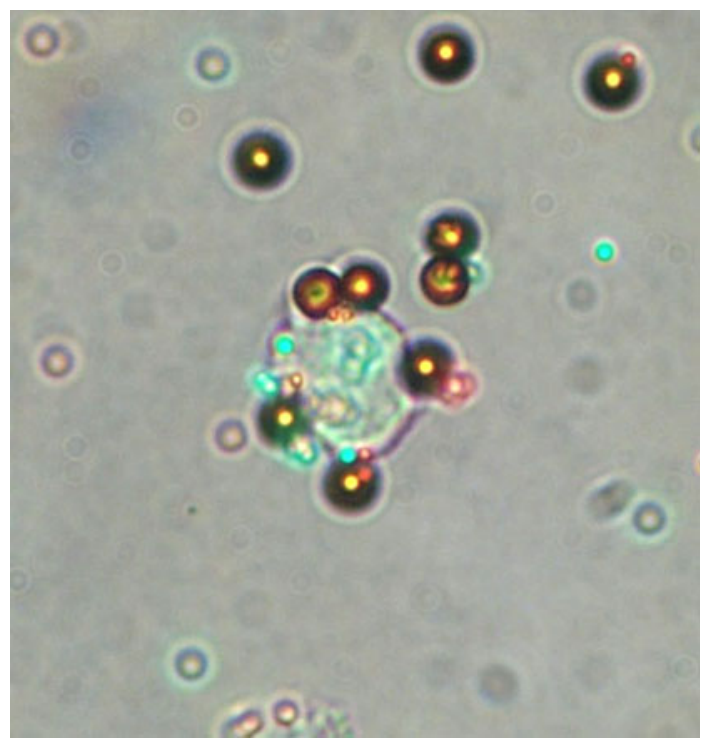

Fig. 5 Isolated tumor cell detected by immunomagnetic target cell selection from bone marrow aspirate in an advanced PCa patient. Green is EGFR and red is HER2 (color figure online) marker [63, 64]. Additional therapeutic benefits might be captured if tumor dynamics from repeated DTC analysis is performed [60].

We hypothesize that CTCs have phenotypically detectable characteristics related to homing. Especially the BM environment with its hypoxic acidity might be the best suitable fit for functionally glycolytic disseminated cells. Clinical evidence also suggests that patients with tumors that contain more hypoxic areas have higher rates of metastases [65]. This is a strong link to CTCs, where tumor hypoxia may be important in selecting and determining the metastatic ability of CTCs, as well as their progression once secondary tumor metastases are established. Still, it is not known if circulating cells function as early metastatic founders in ectopic sites, as proposed by Klein et al. [66], or indicate late linear clonal acceleration in tumorigenesis [67]. Despite these unsolved questions, hypoxia is a potent candidate for preparing disseminated CTCs to a beneficial adapted cellular program conferring survival in distant sites. EGF and other kinases may function as a link between EMT in PCa and bone and lymph node homing, by its ability to recruit $\mathrm{BM}$ progenitor cells inducing autophagy and, thus, improving their chance to survive in a hypoxic glycolytic niche. Similarly, the EGFR and HER2 axis may be important in detached cell survival, rescuing ATP supply and protecting CTCs from apoptosis [68]. Also in the state of homing to the bone EGF secreted from DTCs could stimulate osteoblast progenitors changing the receptor activator for nuclear factor $\kappa \mathrm{B}$ (RANK)/osteoprotegerin (OPG) ratio. However, during the process of undetachment, relevant DTCs must undergo EMT and incorporate stem cell-like features [69]. In the state of EMT, embryonic markers are overexpressed, such as Vimentin, N-cadherin and the RANK ligand (RANKL) protein, promoting $\mathrm{PCa}$ progression [70]. Like-wise, genetic markers related to EMT, as Snail and Twist, are upregulated in PCa. In this model, the primary tumor will be highly responsive to EMT-inducing signals and confer this potential to dissemination. Especially, RANK-bearing DTCs have been linked to migration and are preferentially attracted to a RANKL-enhanced environment, as encountered in the BM [71].

This may imply that these cells have stem cell-like properties and are capable to settle in hostile acidic BM conditions in a state of dormancy [41]. When these persisting cells wake up and initiate a micrometastasis, they appear genotypically more equal to their primary tumor, independent of the cause of loss of immunosurveillance [72]. Thus, detecting the disease stage by addressing the interplay between the soil (bone marrow, lymph nodes and other organs) and the seeds (primary tumor and isolated tumor cells) will be mandatory for adequate successful intervention. 


\section{Conclusions}

Realizing the heterogeneity of prostate cancer, one has to be aware of the different disease risk features and take into account the life-time risk of relapse and try to reduce radical overtreatment in those where treatment is unnecessary and actively treat those where cure is possible ("theragnostics"). Patients with advanced androgen sensitive disease should be encouraged to enter clinical studies. The design of these protocols should encompass signal changes in key mediators of growth and progression in transformed cells as described in this review. Further scientific work on "theragates" should implement characterized novel biomarkers and address their interplay with radiotherapy in a concept of personalized targeted therapy.

Acknowledgments The authors thank Knut Håkon Hole, MD, Department of Radiology, The Norwegian Radium Hospital, Oslo University Hospital, for providing the MRI figure. K. Røe received financial support from the the South-Eastern Norway Regional Health Authority (grant 2009070).

Conflict of interest K. Røe and W. Lilleby have no conflict of interests. F. Solca is an employee of Boehringer Ingelheim RCV $\mathrm{GmbH} \&$ Co KG.

Open Access This article is distributed under the terms of the Creative Commons Attribution Noncommercial License which permits any noncommercial use, distribution, and reproduction in any medium, provided the original author(s) and source are credited.

\section{References}

1. Widmark A, Klepp O, Solberg A, Damber JE, Angelsen A, Fransson P, Lund JA, Tasdemir I, Hoyer M, Wiklund F, Fossa SD (2009) Endocrine treatment, with or without radiotherapy, in locally advanced prostate cancer (SPCG-7/SFUO-3): an open randomised phase III trial. Lancet 373:301-308

2. Gossage L, Eisen T (2010) Targeting multiple kinase pathways: a change in paradigm. Clin Cancer Res 16:1973-1978

3. Yang J, Weinberg RA (2008) Epithelial-mesenchymal transition: at the crossroads of development and tumor metastasis. Dev Cell $14: 818-829$

4. Kurhanewicz J, Vigneron D, Carroll P, Coakley F (2008) Multiparametric magnetic resonance imaging in prostate cancer: present and future. Curr Opin Urol 18:71-77

5. Riches SF, Payne GS, Morgan VA, Sandhu S, Fisher C, Germuska M, Collins DJ, Thompson A, deSouza NM (2009) MRI in the detection of prostate cancer: combined apparent diffusion coefficient, metabolite ratio, and vascular parameters. AJR Am J Roentgenol 193:1583-1591

6. Akin O, Hricak H (2007) Imaging of prostate cancer. Radiol Clin North Am 45:207-222

7. Choi YJ, Kim JK, Kim N, Kim KW, Choi EK, Cho KS (2007) Functional MR imaging of prostate cancer. Radiographics 27:63-75

8. DeSouza NM, Riches SF, Vanas NJ, Morgan VA, Ashley SA, Fisher C, Payne GS, Parker C (2008) Diffusion-weighted magnetic resonance imaging: a potential non-invasive marker of tumour aggressiveness in localized prostate cancer. Clin Radiol 63:774-782

9. Normanno N, Gullick WJ (2006) Epidermal growth factor receptor tyrosine kinase inhibitors and bone metastases: different mechanisms of action for a novel therapeutic application? Endocr Relat Cancer 13:3-6

10. Yarden Y, Sliwkowski MX (2001) Untangling the ErbB signalling network. Nat Rev Mol Cell Biol 2:127-137

11. Shah RB, Ghosh D, Elder JT (2006) Epidermal growth factor receptor (ErbB1) expression in prostate cancer progression: correlation with androgen independence. Prostate 66:1437-1444

12. Di Lorenzo G, Tortora G, D’Armiento FP, De Rosa G, Staibano S, Autorino R, D'Armiento M, De Laurentiis M, De Placido S, Catalano G, Bianco AR, Ciardiello F (2002) Expression of epidermal growth factor receptor correlates with disease relapse and progression to androgen-independence in human prostate cancer. Clin Cancer Res 8:3438-3444

13. Raben D, Bianco C, Helfrich B, Weng E, Ciardiello F, Harari P (2002) Interference with EGFR signaling: paradigm for improving radiation response in cancer treatment. Expert Rev Anticancer Ther 2:461-471

14. Strachan L, Murison JG, Prestidge RL, Sleeman MA, Watson JD, Kumble KD (2001) Cloning and biological activity of epigen, a novel member of the epidermal growth superfamily. J Biol Chem 276:18265-18271

15. De Luca A, Carotenuto A, Rachiglio A, Gallo M, Maiello MR, Aldinucci D, Pinto A, Normanno N (2008) The role of the EGFR signaling in tumor microenvironment. J Cell Physiol 214:559-567

16. Nyati MK, Morgan MA, Feng FY, Lawrence TS (2006) Integration of EGFR inhibitors with radiochemotherapy. Nat Rev Cancer 6:876-885

17. Herbst RS (2004) Review of epidermal growth factor receptor biology. Int J Radiat Oncol Biol Phys 59:21-26

18. Chen DJ, Nirodi CS (2007) The epidermal growth factor receptor: a role in repair of radiation-induced DNA damage. Clin Cancer Res 13:6555-6560

19. Bianco C, Tortora G, Bianco R, Caputo R, Veneziani BM, Caputo R, Damiano V, Troiani T, Fontanini G, Raben D, Pepe S, Bianco AR, Ciardiello F (2002) Enhancement of antitumor activity of ionizing radiation by combined treatment with the selective epidermal growth factor receptor-tyrosine kinase inhibitor ZD1839 (Iressa). Clin Cancer Res 8:3250-3258

20. Baumann M, Krause M (2004) Targeting the epidermal growth factor receptor in radiotherapy: radiobiological mechanisms, preclinical and clinical results. Radiother Oncol 72:257-266

21. Baumann M, Krause M, Dikomey E, Dittmann K, Dorr W, Kasten-Pisula U, Rodemann HP (2007) EGFR-targeted anti-cancer drugs in radiotherapy: preclinical evaluation of mechanisms. Radiother Oncol 83:238-248

22. Shi F, Telesco SE, Liu Y, Radhakrishnan R, Lemmon MA (2010) ErbB3/HER3 intracellular domain is competent to bind ATP and catalyze authophosphorylation. Proc Natl Acad Sci USA 107: 7692-7697

23. Campbell MR, Amin D, Moasser MM (2010) HER3 comes of age: new insights into its functions and role in signaling, tumor biology, and cancer therapy. Clin Cancer Res 16:1373-1383

24. Carpenter G (2003) ErbB-4: mechanism of action and biology. Exp Cell Res 284:66-77

25. Mellinghoff IK, Vivanco I, Kwon A, Tran C, Wongvipat J, Sawyers CL (2004) HER2/neu kinase-dependent modulation of androgen receptor function through effects on DNA binding and stability. Cancer Cell 6:517-527

26. Pignon JC, Koopmansch B, Nolens G, Delacroix L, Waltregny D, Winkler R (2009) Androgen receptor controls EGFR and ERBB2 gene expression at different levels in prostate cancer cell lines. Cancer Res 69:2941-2949 
27. Jain A, Penuel E, Mink S, Schmidt J, Hodge A, Favero K, Tindell C, Agus DB (2010) HER kinase axis receptor dimer partner switching occurs in response to EGFR tyrosine kinase inhibition despite failure to block cellular proliferation. Cancer Res 70:1989-1999

28. Dittmann K, Mayer C, Fehrenbacher B, Schaller M, Raju U, Milas L, Chen DJ, Kehlbach R, Rodemann HP (2005) Radiationinduced epidermal growth factor receptor nuclear import is linked to activation of DNA-dependent protein kinase. J Biol Chem 280:31182-31189

29. Harari PM, Huang SM (2000) Modulation of molecular targets to enhance radiation. Clin Cancer Res 6:323-325

30. Toulany M, Dittmann K, Kruger M, Baumann M, Rodemann HP (2005) Radioresistance of K-Ras mutated human tumor cells is mediated through EGFR-dependent activation of PI3K-AKT pathway. Radiother Oncol 76:143-150

31. Dent P, Reardon DB, Park JS, Bowers G, Logsdon C, Valerie K, Schmidt-Ullrich R (1999) Radiation-induced release of transforming growth factor alpha activates the epidermal growth factor receptor and mitogen-activated protein kinase pathway in carcinoma cells, leading to increased proliferation and protection from radiation-induced cell death. Mol Biol Cell 10:2493-2506

32. Dent P, Yacoub A, Contessa J, Caron R, Amorino G, Valerie K, Hagan MP, Grant S, Schmidt-Ullrich R (2003) Stress and radiation-induced activation of multiple intracellular signaling pathways. Radiat Res 159:283-300

33. Joensuu G, Joensuu T, Nokisalmi P, Reddy C, Isola J, Ruutu M, Kouri M, Kupelian PA, Collan J, Pesonen S, Hemminki A (2010) A Phase I/II trial of Gefitinib given concurrently with radiotherapy in patients with nonmetastatic prostate cancer. Int J Radiat Oncol Biol Phys 78:42-49

34. Ciardiello F, Caputo R, Bianco R, Damiano V, Fontanini G, Cuccato S, De Placido S, Bianco AR, Tortora G (2001) Inhibition of growth factor production and angiogenesis in human cancer cells by ZD1839 (Iressa), a selective epidermal growth factor receptor tyrosine kinase inhibitor. Clin Cancer Res 7:1459-1465

35. Huang SM, Li J, Armstrong EA, Harari PM (2002) Modulation of radiation response and tumor-induced angiogenesis after epidermal growth factor receptor inhibition by ZD1839 (Iressa). Cancer Res 62:4300-4306

36. Jain RK (2005) Normalization of tumor vasculature: an emerging concept in antiangiogenic therapy. Science 307:58-62

37. Zips D, Baumann M (2003) Anti-VEGF strategies in combination with radiotherapy. In: Nieder C, Milas L, Ang K (eds) Modification of radiation response. Springer, Berlin, pp 79-188

38. Røe K, Seierstad T, Kristian A, Mikalsen LT, Mælandsmo GM, van der Kogel AJ, Ree AH, Olsen DR (2010) Longitudinal magnetic resonance imaging-based assessment of vascular changes and radiation response in androgen-sensitive prostate carcinoma xenografts under androgen-exposed and androgendeprived conditions. Neoplasia 12:818-825

39. Lu Y, Liang K, Li X, Fan Z (2007) Responses of cancer cells with wild-type or tyrosine kinase domain-mutated epidermal growth factor receptor (EGFR) to EGFR-targeted therapy are linked to downregulation of hypoxia-inducible factor-1alpha. Mol Cancer 6:63

40. Bartkowiak K, Effenberger KE, Harder S, Andreas A, Buck F, Peter-Katalinic J, Pantel K, Brandt BH (2010) Discovery of a novel unfolded protein response phenotype of cancer stem/progenitor cells from the bone marrow of breast cancer patients. J Proteome Res 9:3158-3168

41. Gupta PB, Chaffer CL, Weinberg RA (2010) Cancer stem cells: mirage or reality? Nat Med 15:1010-1012

42. Kelly K, Chansky K, Gaspar LE, Albain KS, Jett J, Ung YC, Lau DH, Crowley JJ, Gandara RR (2008) Phase III trial of maintenance gefitinib or placebo after concurrent chemoradiotherapy and docetaxel consolidation in inoperable stage III non-small-cell lung cancer: SWOG S0023. J Clin Oncol 26:2450-2456

43. Greulich H, Chen TH, Feng W, Janne PA, Alvarez JV, Zappaterra M, Bulmer SE, Frank DA, Hahn WC, Sellers WR, Meyerson M (2005) Oncogenic transformation by inhibitor-sensitive and -resistant EGFR mutants. PLoS Med 2:e313

44. Kwak EL, Sordella R, Bell DW, Godin-Heymann N, Okimoto RA, Brannigan BW, Harris PL, Driscoll DR, Fidias P, Lynch TJ, Rabindran SK, McGinnis JP, Wissner A, Sharma SV, Isselbacher KJ, Settleman J, Haber DA (2005) Irreversible inhibitors of the EGF receptor may circumvent acquired resistance to gefitinib. Proc Natl Acad Sci USA 102:7665-7670

45. Kobayashi S, Ji H, Yuza Y, Meyerson M, Wong KK, Tenen DG, Halmos B (2005) An alternative inhibitor overcomes resistance caused by a mutation of the epidermal growth factor receptor. Cancer Res 65:7096-7101

46. Solca F, Baum A, Guth B, Colbatzky F, Blech S, Amelsberg A, Himmelsbach F (2005) BIBW2992, an irreversible dual EGFR/ HER2 receptor tyrosine kinase inhibitor for cancer therapy. Proc AACR-NCI-EORTC International conference on molecular targets and cancer therapeutics, Philadelphia, PA, 118 (abstract A244)

47. Li D, Ambrogio L, Shimamura T, Kubo S, Takahashi M, Chirieac LR, Padera RF, Shapiro GI, Baum A, Himmelsbach F, Rettig WJ, Meyerson M, Solca F, Greulich H, Wong KK (2008) BIBW2992, an irreversible EGFR/HER2 inhibitor highly effective in preclinical lung cancer models. Oncogene 27:4702-4711

48. Regales L, Gong Y, Shen R, de Stanchina E, Vivanco I, Goel A, Koutcher JA, Spassova M, Ouerfelli O, Mellinghoff IK, Zakowski MF, Politi KA, Pao W (2009) Dual targeting of EGFR can overcome a major drug resistance mutation in mouse models of EGFR mutant lung cancer. J Clin Invest 119:3000-3010

49. Schütze C, Dorfler A, Eicheler W, Zips D, Hering S, Solca F, Baumann M, Krause M (2007) Combination of EGFR/HER2 tyrosine kinase inhibition by BIBW 2992 and BIBW 2669 with irradiation in FaDu human squamous cell carcinoma. Strahlenther Onkol 183:256-264

50. Eskens FA, Mom CH, Planting AS, Gietema JA, Amelsberg A, Huisman H, van Doorn L, Burger H, Stopfer P, Verweij J, de Vries EG (2008) A phase I dose escalation study of BIBW 2992, an irreversible dual inhibitor of epidermal growth factor receptor 1 (EGFR) and 2 (HER2) tyrosine kinase in a 2-week on, 2-week off schedule in patients with advanced solid tumours. Br J Cancer 98:80-85

51. Yang C, Shih J, Chao T, Tsai C, Yu C, Yang P, Streit M, Shahidi M, Miller VA (2008) Use of BIBW 2992, a novel irreversible EGFR/HER2 TKI, to induce regression in patients with adenocarcinoma of the lung and activating EGFR mutations: preliminary results of a single-arm phase II clinical trial. J Clin Oncol 26:15s (abstract 8026)

52. Yang C, Hirsh V, Cadranel J, Chen Y, Park K, Kim S, Chao T, Oberdick M, Shahidi M, Miller VA (2009) Phase IIb/III doubleblind randomized trial of BIBW 2992, an irreversible, dual inhibitor of EGFR and HER2 plus best supportive care (BSC) versus placebo plus BSC in patients with NSCLC failing 1-2 lines of chemotherapy (CT) and erlotinib or gefitinib (LUXLung1): a preliminary report. J Clin Oncol 27:15s (abstract 8062)

53. Seiwert TY, Clement PM, Cupissol D, Del Campo J, de MontSerrat H, Thurm HC, Blackman AS, Cohen EE (2010) BIBW 2992 versus cetuximab in patients with metastatic or recurrent head and neck cancer (SCCHN) after failure of platinum-containing therapy with a cross-over period for progressing patients: preliminary results of a randomized, open-label phase II study. J Clin Oncol 28:15s (abstract 5501)

54. Rusnak DW, Affleck K, Cockerill SG, Stubberfield C, Harris R, Page M, Smith KJ, Guntrip SB, Carter MC, Shaw RJ, Jowett A, 
Stables J, Topley P, Wood ER, Brignola PS, Kadwell SH, Reep BR, Mullin RJ, Alligood KJ, Keith BR, Crosby RM, Murray DM, Knight WB, Gilmer TM, Lackey K (2001) The characterization of novel, dual ErbB-2/EGFR, tyrosine kinase inhibitors: potential therapy for cancer. Cancer Res 61:7196-7203

55. Cameron D, Casey M, Press M, Lindquist D, Pienkowski T, Romieu CG, Chan S, Jagiello-Gruszfeld A, Kaufman B, Crown J, Chan A, Campone M, Viens P, Davidson N, Gorbounova V, Raats JI, Skarlos D, Newstat B, Roychowedhury D, Paoletti P, Oliva C, Rubin S, Stein S, Geyer CE (2008) A phase III randomized comparison of lapatinib plus capecitabine versus capecitabine alone in women with advanced breast cancer that has progressed on trastuzumab: updated efficacy and biomarker analyses. Breast Cancer Res Treat 112:533-543

56. Di Leo A, Gomez HL, Aziz Z, Zvirbule Z, Bines J, Arbushites MC, Guerrera SF, Koehler M, Oliva C, Stein SH, Williams LS, Dering J, Finn RS, Press MF (2008) Phase III, double-blind, randomized study comparing lapatinib plus paclitaxel with placebo plus paclitaxel as first-line treatment for metastatic breast cancer. J Clin Oncol 26:5544-5552

57. Johnston S, Pippen J Jr, Pivot X, Lichinitser M, Sadeghi S, Dieras V, Gomez HL, Romieu G, Manikhas A, Kennedy MJ, Press MF, Maltzman J, Florance A, O'Rourke L, Oliva C, Steins S, Pegram M (2009) Lapatinib combined with letrozole versus letrozole and placebo as first-line therapy for postmenopausal hormone receptor-positive metastatic breast cancer. J Clin Oncol 27: 5538-5546

58. Normanno N, Tejpar S, Morgillo F, De Luca A, Van Cutsem E, Ciardiello F (2009) Implications for KRAS status and EGFRtargeted therapies in metastatic CRC. Nat Rev Clin Oncol 6: 519-527

59. de Bono JS, Scher HI, Montgomery RB, Parker C, Miller MC, Tissing H, Doyle GV, Terstappen LW, Pienta KJ, Raghavan D (2008) Circulating tumor cells predict survival benefit from treatment in metastatic castration-resistant prostate cancer. Clin Cancer Res 14:6302-6309

60. Nagrath S, Sequist LV, Maheswaran S, Bell DW, Irimia D, Ulkus L, Smith MR, Kwak EL, Digumarthy S, Muzikansky A, Ryan P, Balis UJ, Tompkins RG, Haber DA, Toner M (2007) Isolation of rare circulating tumour cells in cancer patients by microchip technology. Nature 450:1235-1239

61. Talasaz AH, Powell AA, Huber DE, Berbee JG, Roh KH, Yu W, Xiao W, Davis MM, Pease RF, Mindrinos MN, Jeffrey SS, Davis RW (2009) Isolating highly enriched populations of circulating epithelial cells and other rare cells from blood using a magnetic sweeper device. Proc Natl Acad Sci USA 106:3970-3975
62. Roudier MP, Corey E, True LD, Hiagno CS, Ott SM, Vessel RL (2004) Histological, immunophenotypic and histomorphometric characterization of prostate cancer bone metastases. Cancer Treat Res 118:311-339

63. Weckermann D, Polzer B, Ragg T, Blana A, Schlimok G, Arnholdt H, Bertz S, Harzmann R, Klein CA (2009) Perioperative activation of disseminated tumor cells in bone marrow of patients with prostate cancer. J Clin Oncol 27:1549-1556

64. Berg A, Berner A, Lilleby W, Bruland OS, Fossa SD, Nesland JM, Kvalheim G (2007) Impact of disseminated tumor cells in bone marrow at diagnosis in patients with nonmetastatic prostate cancer treated by definitive radiotherapy. Int J Cancer 120: 1603-1609

65. Brizel DM, Scully SP, Harrelson JM, Layfield LJ, Bean JM, Prosnitz LR, Dewhirst MW (1996) Tumor oxygenation predicts for the likelihood of distant metastases in human soft tissue sarcoma. Cancer Res 56:941-943

66. Klein CA (2009) Parallel progression of primary tumours and metastases. Nat Rev Cancer 9:302-312

67. Weinberg RA (2007) Is metastasis predetermined? Mol Oncol 1:263-264

68. Schafer ZT, Grassian AR, Song L, Jiang Z, Gerhart-Hines Z, Irie HY, Gao S, Puigserver P, Brugge JS (2009) Antioxidant and oncogene rescue of metabolic defects caused by loss of matrix attachment. Nature 461:109-113

69. Odero-Marah VA, Wang R, Chu G, Zayzafoon M, Xu J, Shi C, Marshall FF, Zhau HE, Chung LW (2008) Receptor activator of NF-kappaB Ligand (RANKL) expression is associated with epithelial to mesenchymal transition in human prostate cancer cells. Cell Res 18:858-870

70. Schalken JA (2008) Words of wisdom. Re: phase I clinical trial of a selective inhibitor of CYP17, abiraterone acetate, confirms that castration- resistant prostate cancer commonly remains hormone driven. Eur Urol 54:1438-1439

71. Armstrong AP, Miller RE, Jones JC, Zhang J, Keller ET, Dougall WC (2008) RANKL acts directly on RANK-expressing prostate tumor cells and mediates migration and expression of tumor metastasis genes. Prostate 68:92-104

72. Liu W, Laitinen S, Khan S, Vihinen M, Kowalski J, Yu G, Chen L, Ewing CM, Eisenberger MA, Carducci MA, Nelson WG, Yegnasubramanian S, Luo J, Wang Y, Xu J, Isaacs WB, Visakorpi T, Bova GS (2009) Copy number analysis indicates monoclonal origin of lethal metastatic prostate cancer. Nat Med 15:559-565 